\title{
Risk Management of a Commercial Bank's Project Portfolio through Simulation
}

\author{
Zlata Usmanova*, Anna Khanova ${ }^{\dagger}$ \\ Astrakhan State Technical University \\ Astrakhan, Russian Federation \\ *zlata.usmanova@yandex.ru, †akhanova@mail.ru
}

\begin{abstract}
The authors build a simulation model focused on the risk management of a commercial bank's project portfolio with a detailed description of the relevant methodology. The paper explores the logic of the simulation algorithm which is the logical structure of the system functioning model. It obtains insights into the structure and interrelations of submodels in the simulation model of a commercial bank's project portfolio. The authors analyze the identified stochastic factors. The research selects probability distributions for each of the chosen random factors and explores the core processes of the simulation model for the project portfolio of a commercial bank. It describes the components forming the submodels using various presentation methods. The results of the research work are: determined relationships between banking project risk types (input parameters) and the cumulative risk of a commercial bank's project portfolio (resultant indicator), calculation of the cumulative risk in a commercial bank's project portfolio through simulation, completed experiments with the model based on the factorial design.
\end{abstract}

Index Terms-project portfolio, commercial banks, management, stochastic factor, simulation model, banking project, probability distribution, submodel.

\section{INTRODUCTION}

Risk is a crucial component of a commercial bank's project portfolio, materialization of risk factors determines the feasibility of effective portfolio implementation. Ample research by both national and foreign authors focuses on the risk assessment methods in individual projects with extensive mathematical calculations. In particular, methods based on the construction of stochastic network models are studied by Yu.V. Litvin [1], E. D. Solozhentsev [2], D. S. Korneev [3]. The concept of risk tolerance is described in the research by V. A. Akimov, S. P. Voronov, N. N. Radaev [4]. The foreign authors P. Stinson [5] and B. Joel [6] treat the problem of risk assessment in the bank sphere analytically, without an opportunity to connect the current state of an object, various situations arising during activity of commercial bank, scenarios of management decisions with future state of commercial bank's project portfolio.

The known methods of stress-tests applied by the Bank of Russia can estimate the volume of potential loss at expected influence of stress-factors, but they don't determine probability level of shock events, besides algorithms of stress-tests are not formalized.

Most of the covered risk analysis techniques were developed for securities and investment project portfolios. However, these methods cannot be fully applied to assess the cumulative risk in a commercial bank's project portfolio, because they do not factor in banking project types and risk diversity, thus, a commercial bank fails to estimate possible losses across the overall portfolio. This creates a need to establish a methodology geared towards assessing the cumulative risk across a commercial bank's project portfolio through simulation. The use of simulation will maximize risk management of a commercial bank's project portfolio in various cases.

\section{Building a Simulation Algorithm}

The simulated system is a process of forming and assessing banking projects, building a commercial bank's project portfolio with due regard to any restrictions in hand.There is a need to track a whole flow of projects instead of just one. The process of incoming applications for banking projects is of stochastic nature [7], [8].

A handy way of understanding the functioning logic of the simulation model is the construction of a simulation algorithm. At various stages of simulation, generalized and detailed logical diagrams of simulation algorithms, as well as program diagrams are compiled (Fig. 1). That is, to identify future trends and process patterns, it is required to simulate the structure of a commercial bank's project portfolio. The basis for the construction of a simulation model is the structural diagram of a commercial bank's project management. The proposed simulation model is implemented in Arena simulation environment, but the model can be built in any other simulation software based on the schemes and simulation algorithms shown below.

The structure of the simulation model and its division into submodels follows the project management principles described above. The simulation model of a commercial bank's project portfolio features 5 submodels, all of which help to build and evaluate a commercial bank's project portfolio:

- $S_{\text {org }}$ - submodel Organizational Banking Projects,

- $S_{i n v}$ - submodel Investment Banking Projects,

- $S_{t e h}$ - submodel Technical Banking Projects,

- $S_{r a z}$ - submodel Development Banking Projects,

- $S_{\text {ris }}$ - submodel Risk Assessment.

Based on the simulation algorithm, we have built its logical scheme, which is the logical structure model of the system functioning process [9], [10]. However, the construction of a 


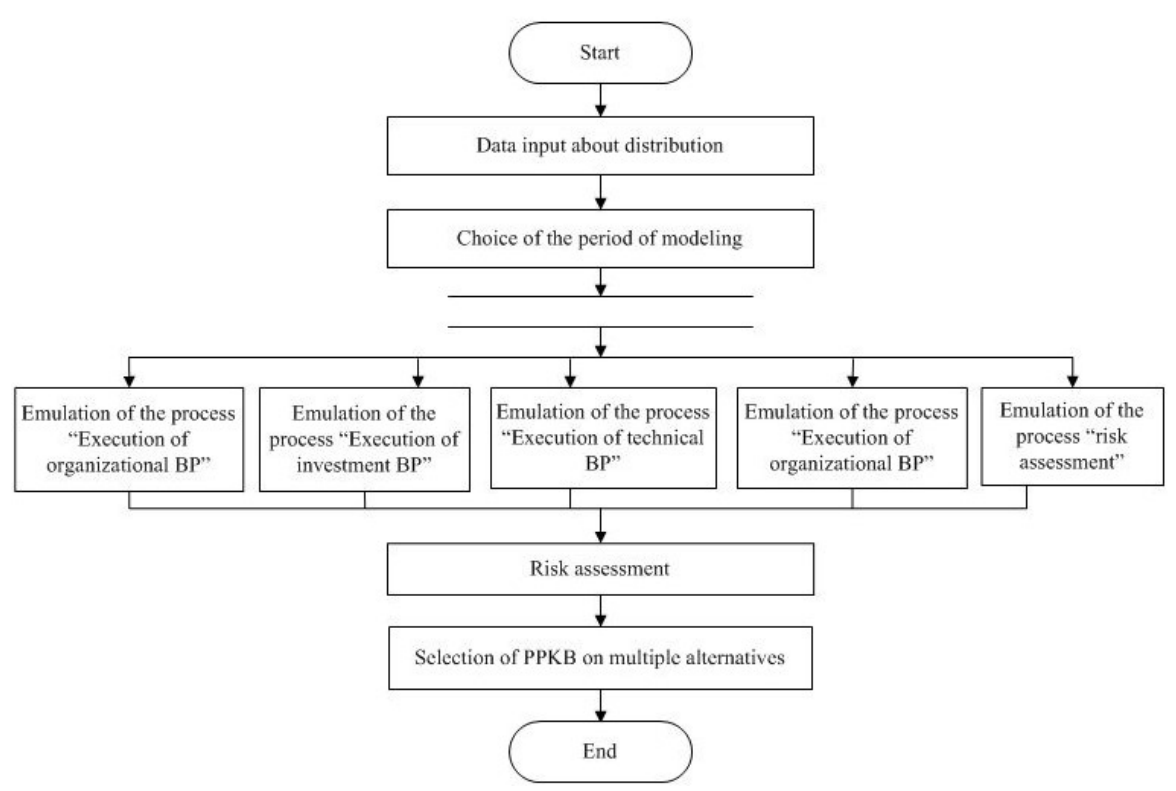

Fig. 1. Simulation algorithm in detail

simulation model for a commercial bank's project. portfolio is feasible only if the set simulation parameters are available.

\section{Selecting Model Parameters}

The functioning of almost any real economic system is subject to random factors. For the simulation model of a commercial bank's project portfolio, the following random factors can be identified:

- percentage of diverse types of banking projects;

- duration of banking projects.

Random factors are define don the basis of consultations with experts from various structural divisions of commercial bank, studying of specialized literature relating work of banking system, project and risk management.

\section{A. Classification of Risk Types Typical for Commercial Banks}

A separate category consists of random factors classified by the types of banking risks they cause:

1) Operational risk:

- probability error in payment transactions;

- probability of errors in planning the budget of a banking project;

- probability of downtime due to external factors;

- growing costs of business processes.

2) Investment risk:

- probability of depositearly withdrawals;

- probability of decreased asset liquidity;

- probability of decreased funding liquidity;

- probability of volatility in the exchange rate of securities in a commercial bank's investment portfolio.

3) Currency risk:
- probability of adverse volatility in the exchange rate of the national currency against foreign currencies;

- probability of changes in income amounts generated abroad when converted into the national currency.

4) Credit risk:

- probability of late interest payment, as a result, a decrease in the liquidity of a commercial bank;

- probability of borrower insolvency.

5) Legal risk:

- probability of changes in the laws governing the banking sector;

- probability of changes in the key interest rate;

- probability of default.

The risk factors set as distributions affect the final simulation result of a commercial bank's project portfolio and decision-making.

\section{B. Choosing simulation scheme}

The academic sources offer a number of simulation schemes based on various methods of inputting random input data into the model. All of them are based on determining the parameters of empirical distributions and testing statistical hypotheses using fitting criteria, on whether available empirical data are consistent with the known laws of distribution. Let us review them.

1) A scheme based on the use of obtained data directly during simulation. In some sources, such method is named tracked simulation. Its disadvantages include the inability to reproduce precedent data and the difficulty to anticipate a sufficient amount of data necessary to complete all runs of the simulation model [11], [12].

2) A scheme with the predetermined empirical distribution function. If, during simulation, it is required to determine 
the value of a random factor, the choice from the indicated distribution stakes place at this moment.

3) A scheme based on the previously obtained theoretical distribution. It follows the same principle as scheme 2 . The difference is in the type of chosen distribution.

For the simulation model of a commercial bank's project portfolio, we used schemes 2 and 3. To do that, one must identify the correspondence of input random variables to certain distributions in time, due to the generation of random variables from these distributions. To determine the laws of distributions of the simulation model for a commercial bank's project portfolio, the following steps must be taken:

- preliminary choice of a set of theoretical distribution;

- estimation of distribution parameters;

- testing the hypothesis whether the made choice is correct;

- verification of findings by comparing the calculated and real data.

Statistical data on random factors was collected during technical and economic analysis of commercial bank's project activity. Selection of functions of parent distribution of probabilities for statistical data on random factors is carried out in the Input Analyzer application (a component of simulation modeling environment Arena), as well as parameters of distributions are estimated and indexes of compliance of distribution to the available data are calculated.

To check the correctness of the chosen function of theoretical distribution, we used a chi-squared test (Pearson fitting criterion). As a result, p-value meaning the maximum error probability in the normal distribution is the smallest. Thus, normal distribution is suitable for the studied statistical values at a commercial bank. In the future, it is planned to change and adjust the values of input parameters in order to plan and experiment with the simulation model.

Using the scheme of the simulation algorithm, we have built a simulation model of a commercial bank's project portfolio in Arena simulation environment.

\section{Estimating The CUMUlative Risk IN A COMMERCIAL BANK's Project PORTFOlio}

The core processes of the simulation model for a commercial bank's project portfolio feature submodels describing the processing of certain-type banking projects (organizational, investment, technical, development). Organizational projects in commercial bank relate to changes in organizational structure and are carried out by human resources department under control of top management. Investment projects of the bank are relating execution of foreign currency transactions and operations with securities. Technical projects include business processes automation, new software training for personnel, introduction and maintenance of equipment. The group of development projects consists of bank projects relating to development of products and services, start up of offices and representative bodies.

The simulation model also tackles the task of estimating the cumulative risk in a commercial bank's project portfolio.
Let us explore one of the submodels of a commercial bank's project portfolio simulation model (Fig. 1), i.e. Risk Assessment submodel, which helps to simulate impact processes of various risk types on the built project portfolio and estimate the cumulative risk level (Fig. 2). The key parameters of the simulated system are banking project risk types, and the cumulative risk in a commercial bank's project portfolio:

$$
K r=f\left(t r_{1}, \ldots, t r_{n r}\right)
$$

where $t r_{1}, \ldots, t r_{n r}$ are risk-variables (banking project risk types being random variables); $n r$ is the number of riskvariables; $K r$ is the cumulative risk in a commercial bank's project portfolio. The cumulative risk in a commercial bank's project portfolio $K r$ is the resultant indicator, while the variables are considered the assessments of risk types per each banking project in the portfolio.

Let us consider the distribution of risk types in a commercial bank's project portfolio normal. To simulate a normally distributed random variable, the central limit theorem (CLT) is applied. Let is build a theorem to simulate the distributions across risk types in a commercial bank's project portfolio, where $t r_{1}, \ldots, t r_{n r}$ are independent equally distributed random variables with the average $\alpha$ and dispersion $\sigma^{2}$, where $n r \rightarrow$ $\infty$ is the distribution function for the centered and standardized amount:

$$
\frac{S r-n r \cdot \alpha}{\sqrt{n r \cdot \alpha}}
$$

where $S r=t r_{1}, \ldots, t r_{n r}$, approximates the distribution function of the standard Gaussian value. Estimating the cumulative risk, one cannot be guided by the number of individual project risks, because diversification reduces any probable total losses dramatically.

Let us determine the relationship between risk types across banking projects (in-put parameters) and the cumulative risk in a commercial bank's project portfolio (resultant indicator).

We apply the approach that ranks risks by priority in a commercial bank's project portfolio, for this, each risk type tr is assigned severity coefficient based on risk significance [10], [13]. The maximum coefficient is given to risks that are most significant for banking projects, the minimum - to the lowest risks. Here, non-negativity of severity coefficients and the equalization of their sum to one are crucial [14].

Let us take the cumulative risk in a commercial bank's project portfolio $K r$ as the sum of risk types across the portfolio projects, which are random variables, the change of which may affect the efficiency of a commercial bank's project portfolio and the amount of anticipated profit weighted by the size of items at risk:

$$
K r=\sum_{i k=1}^{n k} \sum_{i r=1}^{n r}\left(w_{i r} \cdot t r_{i r}\right),
$$

where $w_{i r}$ means the weight of a banking project risk type, $\sum w_{i r}=1, t r_{i r}$ is the metric of banking project risk type levels, $n r$ is the number of considered banking project risk 


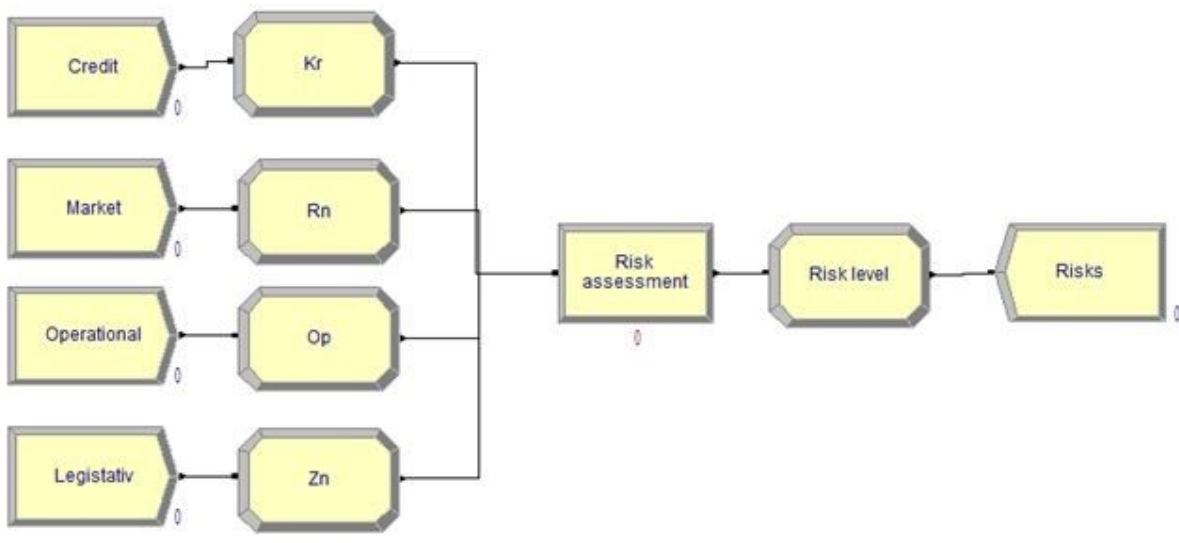

Fig. 2. Risk Assessment submodel

types $i r=1, \ldots, n r, n k$ is the number of projects in a commercial bank's project portfolio $n k=1, \ldots, n k$.

The Risk Assessment module emulates the process of calculating the cumulative risk in a commercial bank's project portfolio using Monte Carlo method. The simulation process generates pseudo-random numbers, each new number considered as a value of the distribution function for the corresponding risk type of the banking project. The model recalculates the cumulative risk of a commercial bank's project portfolio for each new simulation experiment. The use of simulation helps to avoid bias in assessing the cumulative risk of a commercial bank's project portfolio. Knowing the probabilistic parameter distributions in a commercial bank's project portfolio and the relationship between the parameter changes (correlation), the model helps to estimate the cumulative risk in the project portfolio [6], [15].

The simulation model for a commercial bank's project portfolio helps to build a project portfolio and estimate its cumulative risk [16]. The created project portfolio of commercial bank represents the management decision since selection of projects from multiple alternatives is defining what products and services shall be performed and what activities shall be in priority.

\section{Planning Experiments With the Simulation} MODEL

A simulation experiment is the implementation of a computer-aided simulation model with alternative system configurations, studying and comparing findings [13], [16].

In the terminology of experiment planning, input variables and structural assumptions that make up the simulation model are named factors, and the output performance is called responses. To run experiments with the simulation model fora commercial bank's project portfolio, four main factors are identified: budget of the project portfolio; duration of the project portfolio; number and composition of personnel engaged in a banking project; ratio of diverse types of banking projects in the portfolio [3], [17].

These factors are manageable, that is, controllable by bank managers in reality. Manageable factors in the planning of simulation experiments are better, because they have the greatest impact on any decisions connected with the actual formation of a commercial bank's project portfolio [18].

If the simulation model features more than one factor, running simulation with different factor values and building a confidence interval for the anticipated response seems ineffective due to complex calculations and the lack of studying the interaction among the reviewed factors. With the number of factors $k \geq 2$, a technique is used to evaluate the interaction of factors and reduce the number of simulation runs of the model factorial design $2^{k}$.

This method involves choosing two levels for each factor, and then performing simulation runs for each of $2^{k}$ possible combinations of factor levels, called design points. Factor levels are usually denoted by the signs "+" and "-", where "+" corresponds to a larger factor number, "-" to a smaller one.

Next, a design matrix is compiled, representing an array with factor levels and response values $R_{i}$ (a variable containing response values when simulating i combination of factor levels). The compilation of the design matrix helps to calculate the effects of changes in factor levels and the interactions between them [12], [19].

To calculate the effect of changes in the factor level $j$, a value is used that is called the main effect of a factor. The main effect of a factor $j$ is denoted as $(G e)$ this is the average value of a change in response $R_{i}$, caused by the shift of factor $j$ from the level "-" to "+", while the rest of factors remain unchanged. We calculate the main effect of a factor $(G e)$ according to the design matrix as scalar multiplication of the column containing the changes of factor $j$, and column response $R_{i}$ divided by $2^{k-1}$.

To measure the impact of factors, the value named "interaction effect" $(E v)$ is applied. The interaction effect of two factors $j_{1}$ and $j_{2}$ is determined as half of the difference between the average effect of factor $j_{1}$, when factor $j_{2}$ is at "+" (with all the rest factors, except $j_{1}$ and $j_{2}$, remaining unchanged), and the average effect of factor $j_{1}$, when factor $j_{2}$ is at "-.".

To experiment with the simulation model of a commercial bank's project portfolio, let us choose the following factors: "budget of a commercial bank's project portfolio" $B_{f}$; "project 
design. Simulation helps to avoid bias in estimating the

duration" $W_{f}$; "number of organizational banking projects" $O_{f}$; "number of investment banking projects" $I_{f}$; "number of development banking projects" $R_{f}$; "number of technical banking projects" $T_{f}$. Let us build a factorial design of the simulation experiment $2^{6}$. See the lower and upper factor levels in the coding scheme (Table I).

TABLE I

FACTOR CODING SCHEME

\begin{tabular}{lcc}
\hline Factor & - num. value + num. value \\
\hline$B_{f}$ (budget of a project portfolio) & 100 & 150 \\
$W_{f}$ (project duration) & 365 & 730 \\
$O_{f}$ (number of organizational projects) & 10 & 30 \\
$I_{f}$ (number of investment projects) & 30 & 50 \\
$R_{f}$ (number of development projects) & 40 & 60 \\
$T_{f}$ (number of technical projects) & 20 & 40 \\
\hline
\end{tabular}

To calculate the main effects of factors, we have built a matrix of the factorial design, which also indicates the corresponding response variables. As a response, we take the value of the cumulative risk in a commercial bank's project portfolio $(K r)$.

As factors $B_{f}, W_{f}, O_{f}, I_{f}, R_{f}, T_{f}$, make up the percentage of the number of certain-type banking projects in the portfolio, to make the calculations of main effects easy, we assume that when one of these factors increases, the lower level of the other three factors decreases by the amount of the in crease in the changeable factor of the simulation model equally

Let us calculate the main effect for each of the selected factors of the simulation model for a commercial bank's project portfolio. Independent threads are used for each individual response $R_{i}$, where $i=1,2, \ldots, 6$.

The response $(K r)$ is most significantly affected by the growing share of investment projects in a commercial bank's project portfolio $I_{f}$; the average effect of the increase $I_{f}$ from $30 \%$ up to $50 \%$ is the risk increase by $0.57 \%$. We also recorded the growing share of technical projects in the portfolio $T_{f}$; the average effect from the increase $T_{f}$ from $20 \%$ up to $40 \%$ was the risk increase by $0.72 \%$.

The considered realization is one of possibilities at analysis of factors influencing assessment of overall risk of commercial bank project portfolio. Further on it is possible to expand the experiment on the grounds of user's requirements.

\section{CONCLUSION}

The authors built a simulation algorithm for creating a simulation model of a commercial bank's project portfolio. They provide the rationale for making managerial decisions based on the given simulation model. The research helped to list the main types of stochastic factors, classify factors by types of banking risks as a separate category, and determine the structure and the relationship among the components of the simulation model and their features [11], [18]. The results include the calculation of the cumulative risk in a commercial bank's project portfolio through simulation, carried out experiments with the model based on the factorial cumulative risk of a commercial bank's project portfolio. The elaborated simulation model helps, knowing the probabilistic distributions of the project portfolio parameters, as well as the relationship between parameter changes (correlation), to estimate the cumulative risk in a commercial bank's project portfolio.

The expected economic effect of application of the developed simulation model of commercial bank project activity was estimated. The results of calculations confirmed practicability of adoption: the coefficient of net present wort his positive, the index of investments profitability is $7 \%$, term of investment return is slightly more than a year.

\section{REFERENCES}

[1] Litvin Y. V., "Integration of network models of projects and assessment of their risks," Problems of economy and management., vol. 17, no. 24, pp. 46-58, 2013.

[2] Solozhentsev E. D., "Scenario logic-probabilistic risk management in business and technology," 2nd edn. Publishing house "Business Press", $\mathrm{SPb}, 2006$.

[3] Korneev D. S., "Use of neural networks apparatus to create a model of enterprise risk assessment and management," Management of large systems., vol. 17, pp. 81-102, 2007.

[4] Akimov V. A., Voronov S.P. and Radayev N.N., "Concepts of risk and concepts of risk analysis," Strategy of civil protection: problems and research, vol. 2, pp. 562-567, 2013.

[5] Stinson P., "Bank Management and Financial Services," Simon \& Schuster, London., 2019.

[6] Joel B., "Risk Management in banking," John Wiley \& Sons Limited, New York., 2018.

[7] Burkov D.N. and Novikov D.A., "How to manage projects: Scientific and practical publication," SINTAG-GEO, M., 2016.

[8] Greenberg A. S. and Shestakov V. M., "Information Technologies for Modeling Economic Management Programs: A Training Manual for Universities," UNITY-DANA, M., 2003.

[9] Baldin K. V. and Vorobyev S. N., "Risk Management," Gardariki, M., 2015

[10] Blank I. A., "Financial risk management: training course," Elga-N, M., 2016.

[11] Demkin I. V., Streltsov A.V. and Galetov I. D., "Risk Assessment of Investment Projects of Pharmaceutical Enterprise," Risk Management., vol. 4, pp. 16-17, 2004.

[12] Falin G. I.: Risk Analysis Using the Monte Carlo Method. Risk Management., vol. 1, no. 81, pp. 3-19, 2017.

[13] Burkov V. N., Korgin N. A., Novikov D. A. : Introduction to the Theory of Management of Organizational Systems. Librocom, M., 2009.

[14] Slepukhina Y. E., Harchenko G. V.: Peculiarities of modern methods of risk assessment of investment projects. News of Ural State Economic University., vol. 1, no. 18, pp. 103-115, 2007

[15] Khanova A. A., Bondaryeva I. O., Ganyukova N. P. and Erenko O. O., "Simulation Modeling of Business Processes: Training Manual," AGTU, Astrakhan., 2016.

[16] Ignatieva A. V. and Maksimtsov M. M., "Research of Management Systems: Study. Manual for Universities," UNITY-DANA, M., 2013.

[17] Mihic M. M., Dodevska Z. A., Todorovic M. L., Obradovic V. L. and Petrovic D. C., "Reducing Risks in Energy Innovation Projects; Complexity Theory Perspective," Sustainability. vol. 10, pp. 29-36, 2018.

[18] Usmanova Z. A., Risk management of projects in a commercial bank using a logical and probabilistic approach. In the collection: Achievements and prospects of economic science of the new century: practical-oriented aspect., vol. 1, pp. 259-264, 2015.

[19] Usmanova Z. A. and Khanova A. A. "Systematic analysis of factors and processes of decision-making when managing the portfolio of projects of a commercial bank taking into account the development of information and telecommunication technologies," Caspian Journal: Management and High Technologies., vol. 2, pp. 58-71, 2017. 